\title{
History as inspiration: Tracing Franco-Chinese architectural elements in Hanoi old houses
}

\author{
Vu Thi Hanh \\ School of Economics and International Business, Foreign Trade University \\ 91 Chua Lang, Dong Da District, Hanoi 100000, Vietnam \\ Email: hanhvt@ftu.edu.vn
}

Hanoi, September 11, 2019

\begin{abstract}
History is written in textbooks but is indubitably remembered through cultural artifacts and architecture. This is particularly the case when one thinks of Hanoi, the capital city of Vietnam, where its thousands of years of ancient history can be found in the old citadels, and more than half a century of French colonialism can be glimpsed in the Old Quarter houses. Many of these structures have survived the brutality of wars and now feed into the nostalgia of French aesthetic. Yet, in what way can we come to gain greater insight into a cultural space where there is an interconnection between religion, house designs, and forms of feeling? One can find an answer to this question in a newly-published scientific research article titled "Cultural evolution in Vietnam's early 20th century: A Bayesian networks analysis of Hanoi Franco-Chinese house designs" in the Social Sciences and Humanities Open journal of Elsevier.
\end{abstract}

The study is the first of its kind to systematically break down elements of house façade in Hanoi's Old Quarter and examine them against the rich cultural-historical continuity of the city and country as a whole. These are the very old houses that today live on in the oil paintings of the Vietnamese artist Bui Xuan Phai (1920-1988) - whose name intrinsically conjures up images of "Phai streets." The authors, allegedly inspired by Bui Xuan Phai's paintings and the historical remnants in the capital city, make a brave attempt to statistically analyze and remember the Franco-Chinese architecture in Hanoi's historic streets. The old houses, many of which have undergone urbanization and commercialization, are documented through 248 photos taken by one of the co-authors, the Vietnamese artist Bui Quang Khiem in ten years from 2007 to 2018. This approach alone speaks volume to the meticulous preparation and patience in conducting research on cultural history.

It comes as an interesting surprise that the type of research data in this study goes beyond such usual methods as observational, experimental, simulation, and derived. In fact, researchers can make data out of what they observe. In other words, the authors see with their own eyes the actual house façade as well as the photos of Hanoi Old Quarter house façade in order to encrypt these images and their elements into data. Given this approach, the data are inevitably subjective-the authors give their evaluation of the house façade based on their own feelings, knowledge, and judgments about Hanoi ancient architecture. The method to generate input data of the study is exceptional in that from seeing the photos (sense) then receiving information about the architectural decoration of the facade of the old 
houses (perception) to feeling the spirit of old house images (feeling). Feelings of the traditional, feeling of modern and feeling of cultural evolution add extra spatial dimensions of our big three-dimensional space that makes modern, and old Hanoi, are hardly discerned. Since feelings may be colored by personal experience, belief or even memories, the use of quantitative and qualitative data can improve storytelling about Vietnam's culturalarchitectural evolution in a more subtle way.

While the dataset in this study is not large and has its limitations, it stands out in a unique manner-the 72 data lines were recorded through a series of photos of Hanoi old houses characterized by Vietnam's cultural evolution in the early 20th century, hence, the value of the information is constant regardless of time or space. The use of Bayesian networks analysis allows the construction of independent and dependent variables that capture the façade decoration of the old houses as close as possible to the religious culture of Vietnam. For example, regarding Buddhist-inspired decorations façade designs, lotus flowers symbolize spiritual enlightenment and rebirth. Taoist-inspired patterns are represented by a cloud or an octagonal fengshui bagua mirror, meanwhile Chinese characters or paper rolls decorated on the façade of Hanoi old houses are symbols of Confucianism.

Among its notable findings, the authors reveal the high probability of the hybrid value when there is a weak presence of Buddhist-inspired decorative symbols. Additionally, when the decoration of a façade is hybrid, the probability of the cultural evolution happening is at its highest. Understanding these changes requires one to dig deeper into the past, to grasp the historical contexts against which such changes were brought about. And this is why scientific studies of this kind are enormously valuable, even as one may debate its subjectivity and model construction. The knowledge of culture, religion, architectural designs, and scientific explanation are all employed to confirm traces of cultural evolution in the $20^{\text {th }}$ century of Vietnam through the Franco-Chinese style old houses of Hanoi.

Cultural evolution is not easy to study, but this study proves that it is not impossible either. A political empire may have no long existence; an economic policy may need to be revised; human needs may change, and our names will be forgotten. The study reminds us of the long-lasting status of the cultural values of Hanoi Old Quarter.

\section{References}

La, V. P., \& Vuong, Q. H. (2019). bayesvl: Visually Learning the Graphical Structure of Bayesian Networks and Performing MCMC with 'Stan.' The Comprehensive R Archive Network (CRAN). Available from: https://cran.r-project.org/package=bayesvl.

Vuong, Q. H., Bui, Q. K., La, V. P., Vuong, T. T., Ho, M. T., Nguyen, H. K. T., ... \& Ho, M. T. (2019). Cultural evolution in Vietnam's early 20th century: a Bayesian networks analysis of Hanoi Franco-Chinese house designs. Social Sciences \& Humanities Open, 1(1), 1-19; https://doi.org/10.1016/i.ssaho.2019.100001. 